\title{
Quantitative observations on mineralized and non- mineralized bone in the iliac crest
}

\author{
H. A. Ellis AND KATHLEEN M. PEART
}

\author{
From the Department of Pathology, University of Newcastle upon Tyne
}

SYNOPSIS The amounts of mineralized bone and osteoid in thin undecalcified sections of iliac crest have been measured in 68 control subjects at necropsy using a point-counting method. The effect of varying the site selected for quantitative study on the value obtained for total bone mass has been investigated in decalcified sections of iliac crest.

The total bone mass shows individual variation within a fairly constant range with a mean of $22.7 \pm 0.5 \%$ up to the age of 50 years and then progressively falls to a mean of $15.5 \pm 1 \cdot 1 \%$ for individuals aged $>50$ years. Some of the lowest values in the range 5.5 to 16.4 (mean $8.9 \pm 1.9 \%$ ) were observed in elderly women in the seventh to ninth decades. It is concluded that so-called senile osteoporosis is usually a manifestation of a normal aging process. In controls osteoid accounts for only about $0.1 \%$ of the area measured and for a maximum of $1.8 \%$ of bone with a mean mineralization of $99.5 \%$. Osteoid is patchily distributed and the maximum number of birefringent lamellae in any seam is four.

The results of quantitative histology carried out in different parts of the iliac crest indicate that there are variations with the distance of the site from the anterior superior spine and its depth below the crest surface. The importance of this in relation to the site and size of iliac crest biopsies used for quantitative histology is discussed.

There is a significant correlation between the values for total bone mass when estimated by the point-counting technique in undecalcified sections and by a volumetric method using blocks of bone.

Iliac crest bone is commonly used in the diagnosis of metabolic bone disease (Sacker and Nordin, 1954; Beck and Nordin, 1960; Williams and Nicholson, 1963). More recently quantitative histological methods have been applied to determine the amounts of mineralized and non-mineralized bone in a given bone sample (Garner and Ball, 1966; Woods, Morgan, Paterson, and Gossmann, 1968). If such quantitative studies are to be meaningful then the biopsy specimen must be representative. Dunnill, Anderson, and Whitehead (1967) have shown that quantitative changes in total bone mass in the iliac bone do not necessarily parallel those in the vertebral body, but there is little information concerning variations within the iliac bone itself.

During the last four years we have examined more than 300 blocks of iliac crest from control and diseased subjects at necropsy and have been impressed by the variation in density of cancellous trabeculae in different parts of the crest and subjacent bone. This variation may be of no great importance when biopsies are obtained in the vertical plane since Received for publication 27 October 1971. quantitative studies can then be made on bone situated at a standardized distance below the crest surface. However, such biopsies when taken with a narrow trephine of 0.3 to $0.5 \mathrm{~cm}$ diameter are not entirely satisfactory. The amount of material, in our opinion, is often inadequate for quantitative study and fragmentation tends to occur. The recent trend has been towards the use of larger trephines with internal diameters of 0.7 to $1.0 \mathrm{~cm}$ the biopsy being taken in the horizontal plane to include both the outer and inner tables of compact cortical bone. In muscular or obese subjects it may be difficult to be certain of the precise site selected with regard to its distance from the anterior superior spine and depth below the iliac crest surface

The purpose of the present paper is to describe the variations in bone density observed in postmortem samples of iliac bone and to report the correlation of values for cancellous bone mass estimated by quantitative histological and volumetric methods. In addition the results of quantitative histological studies in 68 control iliac crests obtained at necropsy are described. This forms the 
basis for a study of the changes in bone mass in biopsy and postmortem material in patients with chronic renal failure which will be reported separately.

\section{Materials and Methods}

Bone samples were removed at necropsy from the iliac crest at a site 4 to $6 \mathrm{~cm}$ posterior to the anterior superior spine. Adjacent blocks approximately $0.5 \mathrm{~cm}$ thick were sawn out to a depth of up to $4.0 \mathrm{~cm}$. After fixation in neutral $4 \%$ formaldehyde in saline one block was decalcified in a formic acid mixture and paraffin sections were prepared while the other was trimmed to remove some compact cortical bone leaving a block of largely cancellous bone about $1.0 \mathrm{~cm}$ in width and from 1.0 to $2.0 \mathrm{~cm}$ in length. Undecalcified sections were then prepared (Ball, 1957) and stained in aqueous $1 \%$ silver nitrate and counterstained with acridine red or $1 \%$ aqueous toluidine blue.

The control series comprised 68 bone samples obtained at necropsy from cases of sudden death in apparently previously healthy individuals. In 53 $(78 \%)$ death was attributable to trauma or poisoning as a result of accident or suicide. The remainder included 11 cases of myocardial infarction or coronary atherosclerosis and three of subarachnoid haemorrhage. Cases with postmortem evidence of renal, hepatic, gastrointestinal, or malignant disease were excluded.

QUANTITATION OF MINERALIZED AND NONMINERALIZED BONE

In the 68 control cases an area of cancellous bone was delineated on the coverslip of each undecalcified section, extending across the full thickness of the bone between the inner and outer tables of compact bone and from just beneath the level of the cortex of the iliac crest to a depth of about $1.0 \mathrm{~cm}$. The mean area delineated was $0.7 \mathrm{~cm}^{2}$. The proportions of mineralized and non-mineralized bone in this area were estimated by means of a point-counting system similar to that described by Garner and Ball (1966) with a 16 line-intersections rectangular graticule (Graticules Ltd, London, ref. G1) using a $\times 10$ eyepiece and $\times 10$ objective. The graticule was moved in stages over the whole delineated area with as little overlap as possible. The number of hits on intersections varied with the area measured but was about 16500 per $\mathrm{cm}^{2}$ and averaged around 12000 per case. The principle of the method, that the number of intersections on the graticule which coincide on the section with any particular component is proportional to the area of that component, is well established (Dunnill, 1962; Hennig and Meyer-
Arendt, 1963). It was found advantageous to count each section under polarized light since this makes the osteoid more readily discernible.

In addition the number of birefringent lamellae in any osteoid was counted to give an index of the width of osteoid in control bones (Woods et al, 1968).

VARIATIONS IN TOTAL BONE MASS WITHIN THE ILIAC BONE

Iliac bones obtained from seven subjects at necropsy were used (five controls and two cases of chronic $\vec{\omega}$ renal azotaemic osteodystrophy). Blocks about $4 \mathrm{~cm} \stackrel{\text { ? }}{2}$ in length were sawn at intervals of $1.0 \mathrm{~cm}$ com-? mencing approximately $3 \mathrm{~cm}$ posterior to the N anterior superior spine. The total cancellous bone $\rightarrow$ was determined by the point-counting technique in decalcified sections in each block at two or three different levels in the vertical plane. Each level com- 을 prised an area measuring from 0.7 to $1.0 \mathrm{~cm}$ in depth and up to $0.7 \mathrm{~cm}$ in width. In five subjects $\frac{7}{0}$ counts were made in triplicate in each of three vertical levels in two or three adjacent blocks. In the $\overrightarrow{0}$ remaining two cases similar counts were made at $N$ two and three levels respectively, in the vertical $\square$ plane of a single block To investigate the possible effect of rotation of a biopsy sample before embedding, the total cancellous bone mass was determined in decalcified sections prepared from blocks of iliac $\stackrel{\circ}{\mathbb{D}}$ crest cut in two planes at right angles. The effect of $\stackrel{\varrho}{\Rightarrow}$ variation in the size of the area counted was studied $\overline{0}$ in four cases by determining the total bone mass in three concentric squares with sides measuring 0.3 , 0.6 , and $0.9 \mathrm{~cm}$ respectively.

CORRELATION OF TOTAL CANCELLOUS BONE MASS ESTIMATED BY POINT-COUNTING TECHNIQUE AND BY A VOLUMETRIC METHOD

Pieces of unfixed cancellous iliac crest bone measuring approximately $2.0 \times 0.7 \times 0.5 \mathrm{~cm}$ were obtained from 25 subjects at necropsy, including 15 with chronic renal disease. The bone volume was deter-음 mined by water displacement using an Armstrong density bottle (Gallenkamp). The marrow was re- $\rho$ moved under a jet of water, the volumetric deter- $N$ mination repeated, and the proportion of the N original volume occupied by cancellous bone then ${ }_{\sigma}^{\omega}$ calculated. For comparison, the total bone in an undecalcified section prepared from an adjacent $\frac{0}{\frac{0}{C}}$ block of cancellous bone was estimated using the point-counting technique previously described.

\section{Results}

The pattern and density of the cancellous trabeculae within the iliac bone are not uniform. A fairly com 


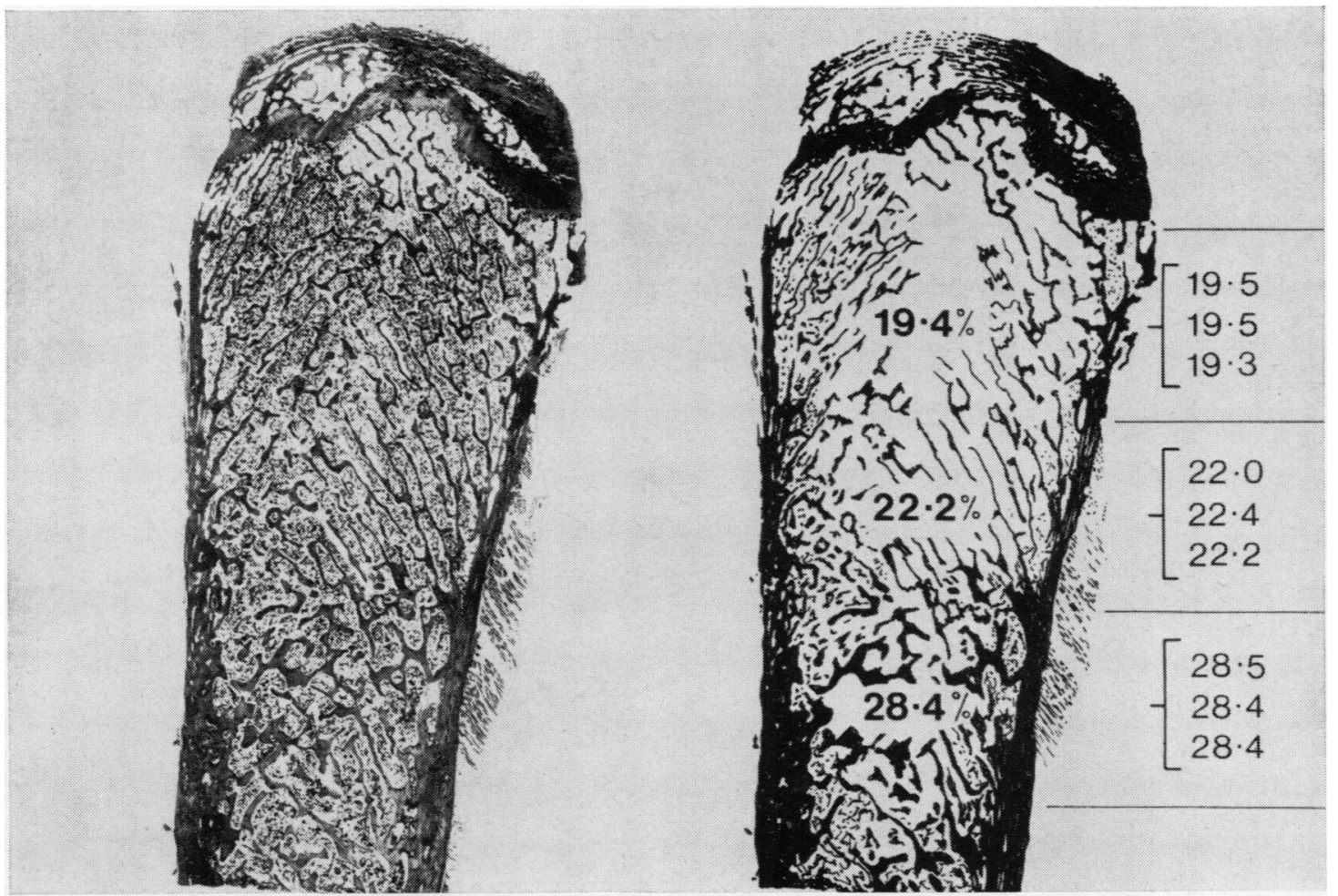

Fig. 1 Section of iliac crest from 19-year-old man showing variation in density of cancellous trabeculae.

Each central figure superimposed on the sketch represents the mean of the three estimations (right) for total bone mass at that level. Decalcified. Haematoxylin and eosin $\times 3 \cdot 3$.

mon finding in control material (Fig. 1) is that the density of trabeculae is highest towards the lower part of the specimen where the two tables of compact cortical bone are close together and lowest immediately below the compact bone forming the surface of the crest midway between the inner and outer tables. In elderly subjects the density of trabeculae is reduced and the trabeculae tend to be more irregularly distributed. In spite of this the trabeculae in old age are not unduly thinned. An extreme example of this is illustrated (Figs. 2 and $3 \mathrm{c}$ ).

Determination of total bone by the point-counting technique generally gives reproducible results to within about $5 \%$ but the error may be greater when the total bone value is very low. The results of multiple counts made in the various horizontal and vertical levels are summarized in Table I. There are differences in the mean values obtained as the area counted varies in the vertical and horizontal planes.

The results of counts made in two planes at right angles indicate that there is a somewhat higher value for total bone in each case when sections are quanti- tated in the vertical plane (mean values of 12.4 and $10.9 \%$ and 15.6 and $13.5 \%$, respectively).

The results of counts made in concentric squares of increasing area (Table II) confirm that the density of cancellous trabeculae is often least in the central part of the iliac crest and increases as the area measured is increased.

\section{CORRELATION OF VOLUMETRIC AND POINT} COUNTING TECHNIQUES

The results obtained are summarized in Figure 4. There is a significant linear correlation for total bone estimated by the two methods (correlation coefficient $r=0.831, \mathrm{P}<0.001)$. The calculated regression line passes very close to the origin (when $y=0, x=0.9$ ) but there is a tendency for values in individual samples of bone to be higher when determined by the volumetric method.

\section{CONTROL GROUP DATA}

The values for total bone, mineralized bone, and osteoid for the 68 cases are given in Tables III and 


\begin{tabular}{|c|c|c|c|c|c|c|c|}
\hline \multirow[t]{3}{*}{ Sex and Age } & \multicolumn{7}{|c|}{ Percentage Measured Area Comprising Total Bone } \\
\hline & \multirow{2}{*}{$\begin{array}{l}\text { Vertical } \\
\text { Level }^{\mathbf{2}}\end{array}$} & \multicolumn{6}{|c|}{ Horizontal Level } \\
\hline & & Block 1 & & Block 2 & & Block 3 & \\
\hline & 1 & $\begin{array}{l}25 \cdot 0 \\
23 \cdot 3 \\
22 \cdot 0\end{array}$ & $23 \cdot 4$ & $\begin{array}{l}17.7 \\
18.5 \\
17.5\end{array}$ & $17 \cdot 9$ & & \\
\hline \multirow[t]{3}{*}{$\begin{array}{l}\text { Male } \\
\text { Age } 14 \text { years }\end{array}$} & 2 & $\begin{array}{l}26 \cdot 5 \\
26 \cdot 4 \\
26 \cdot 4\end{array}$ & $26 \cdot 4$ & $\begin{array}{l}21 \cdot 7 \\
22 \cdot 6 \\
22 \cdot 2\end{array}$ & $22 \cdot 2$ & & \\
\hline & 3 & $\begin{array}{l}22.6 \\
22.0 \\
21.8\end{array}$ & $22 \cdot 1$ & $\begin{array}{l}17.4 \\
17.9 \\
18.0\end{array}$ & $17 \cdot 8$ & & \\
\hline & 1 & $\begin{array}{l}19.2 \\
18.7 \\
19.2\end{array}$ & $19 \cdot 0$ & $\begin{array}{l}21 \cdot 7 \\
22.5 \\
21.5\end{array}$ & 21.9 & $\begin{array}{l}19 \cdot 8 \\
20.2 \\
20 \cdot 2\end{array}$ & $20 \cdot 1$ \\
\hline \multirow[t]{3}{*}{$\begin{array}{l}\text { Male } \\
\text { Age } 22 \text { years }\end{array}$} & 2 & $\begin{array}{l}26 \cdot 8 \\
28 \cdot 3 \\
28 \cdot 2\end{array}$ & $27 \cdot 8$ & $\begin{array}{l}27 \cdot 4 \\
27 \cdot 8 \\
28 \cdot 0\end{array}$ & $27 \cdot 7$ & $\begin{array}{l}25.9 \\
26.0 \\
25.6\end{array}$ & $25 \cdot 8$ \\
\hline & 3 & $\begin{array}{l}24 \cdot 9 \\
24 \cdot 6 \\
25 \cdot 2\end{array}$ & $24 \cdot 9$ & $\begin{array}{l}21 \cdot 8 \\
22 \cdot 2 \\
22 \cdot 5\end{array}$ & $22 \cdot 2$ & $\begin{array}{l}23 \cdot 0 \\
23 \cdot 1 \\
23 \cdot 0\end{array}$ & $23 \cdot 0$ \\
\hline & 1 & $\begin{array}{l}23 \cdot 9 \\
23 \cdot 4 \\
22 \cdot 9\end{array}$ & $23 \cdot 4$ & $\begin{array}{l}20.7 \\
20.8 \\
20.8\end{array}$ & 20.8 & & \\
\hline \multirow[t]{3}{*}{$\begin{array}{l}\text { Male } \\
\text { Age } 24 \text { years }\end{array}$} & 2 & $\begin{array}{l}24 \cdot 6 \\
24 \cdot 2 \\
23 \cdot 9\end{array}$ & $24 \cdot 2$ & $\begin{array}{l}27 \cdot 5 \\
27 \cdot 5 \\
27 \cdot 0\end{array}$ & $27 \cdot 3$ & & \\
\hline & 3 & $\begin{array}{l}28 \cdot 0 \\
27 \cdot 3 \\
28.7\end{array}$ & 28.0 & $\begin{array}{l}28.7 \\
29.1 \\
29.1\end{array}$ & $29 \cdot 0$ & & \\
\hline & 1 & $\begin{array}{l}13 \cdot 6 \\
14.5 \\
14.4\end{array}$ & $14 \cdot 2$ & $\begin{array}{l}12.7 \\
14.4 \\
13.0\end{array}$ & 13.4 & $\begin{array}{l}10 \cdot 6 \\
10 \cdot 7 \\
10 \cdot 2\end{array}$ & 10.5 \\
\hline \multirow[t]{2}{*}{$\begin{array}{l}\text { Female } \\
\text { Age } 93 \text { years }\end{array}$} & 2 & $\begin{array}{l}18 \cdot 0 \\
18 \cdot 1 \\
18.5\end{array}$ & $18 \cdot 2$ & $\begin{array}{l}12.8 \\
14.0 \\
13.6\end{array}$ & 13.5 & $\begin{array}{l}10.3 \\
12.0 \\
11.2\end{array}$ & $11 \cdot 2$ \\
\hline & 3 & $\begin{array}{l}3.9 \\
3.3 \\
3.8\end{array}$ & $3 \cdot 7$ & $\begin{array}{l}4.4 \\
4.6 \\
4.6\end{array}$ & 4.5 & $\begin{array}{l}3 \cdot 6 \\
4 \cdot 1 \\
3.9\end{array}$ & 3.9 \\
\hline
\end{tabular}

Table I Variation in total bone mass in different parts of the iliac crest in four control subjects ${ }^{1}$ At each site the results of three counts and the mean are given.

\begin{tabular}{llcccc}
\hline Square & $\begin{array}{c}\text { Area } \\
\left(\mathrm{cm}^{2}\right)\end{array}$ & \multicolumn{5}{l}{ Percentage Total Bone } \\
\cline { 3 - 6 } & & Case 1 & Case 2 & Case 3 & Case 4 \\
& & & & & \\
\hline Inner & 0.09 & 7.9 & 13.8 & 17.7 & 14.1 \\
Middle & 0.36 & 10.1 & 16.3 & 20.3 & 13.3 \\
Outer & 0.81 & 14.9 & 14.2 & 18.3 & 14.4 \\
\hline
\end{tabular}

Table II Variation in total bone mass value related to area measured

IV and the values for total bone are plotted in relation to age in Figures 5 and 6. The apparent discrepancy between the values for mineralized bone and osteoid and those for total bone and percentage $N$ mineralization in Tables III and IV is attributable to the fact that figures for total bone and mineralized bone are expressed to the first decimal place whereas those for osteoid and percentage mineralization have been calculated from data expressed to two decimal places in order to take account of the small amount of osteoid present in the majority of cases.

Osteoid is recognizable in many of the control bones but is patchily distributed over short lengths of cancellous trabeculae. Many trabeculae appear devoid of osteoid and osteoid accounts for only a small proportion of the total area of bone matrix 


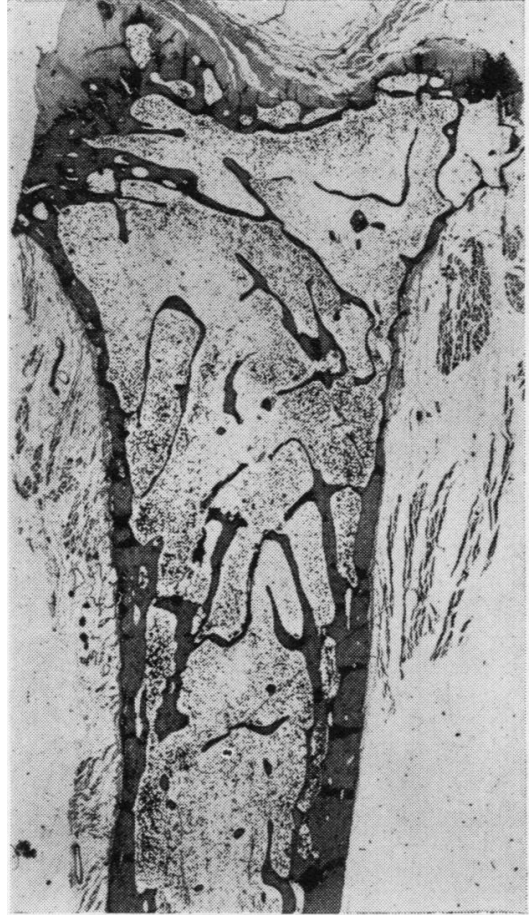

Fig. 2 Section of iliac crest from 93-year-old woman showing greatly reduced total bone mass.

The surviving trabeculae are widely spaced but not thinned. Some trabeculae are thickened. Decalcified. Haematoxylin and eosin $\times 3 \cdot 3$.

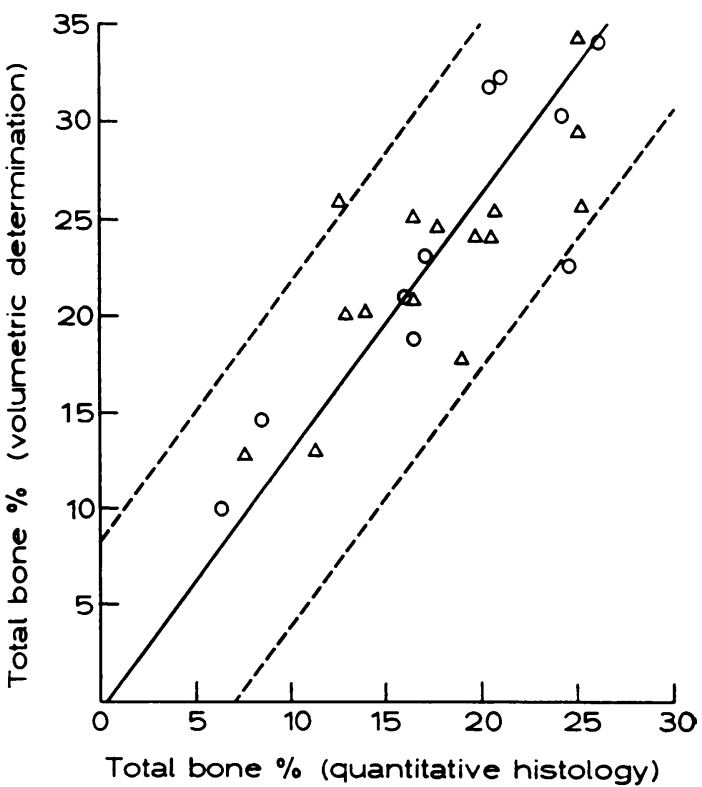

Fig. 4 Linear relationship between values obtained for total bone mass by volumetric method and by quantitative histology.

Continuous and interrupted lines represent calculated regression line and $95 \%$ confidence limits, respectively.

$\triangle$ Chronic renal failure $\bigcirc$ Others

Correlation coefficient $r=+0.831 ; P=0.001$.

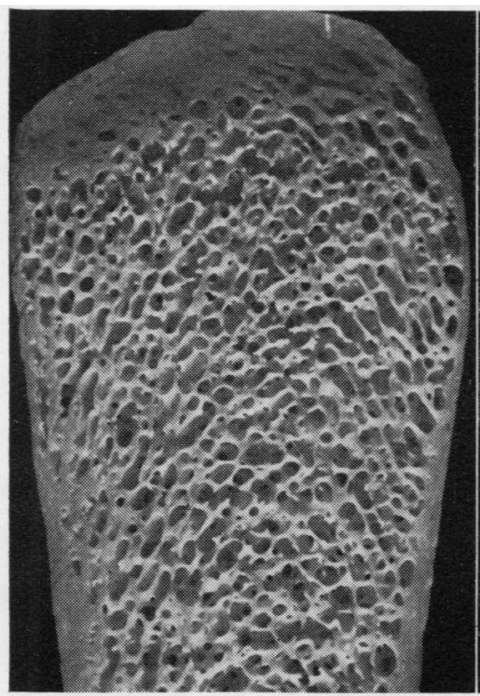

a

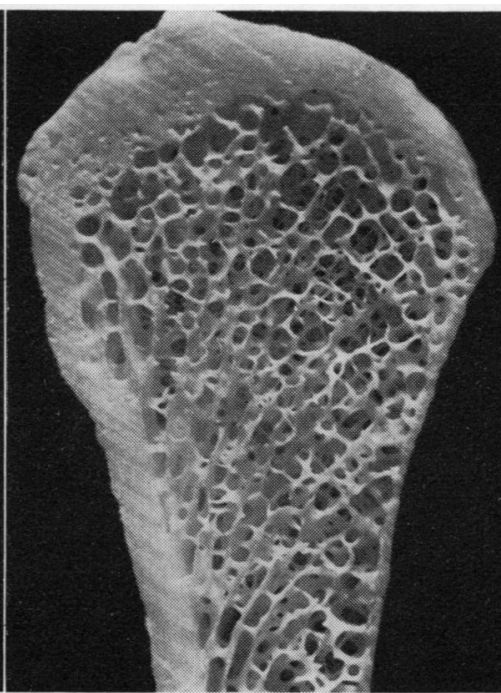

b

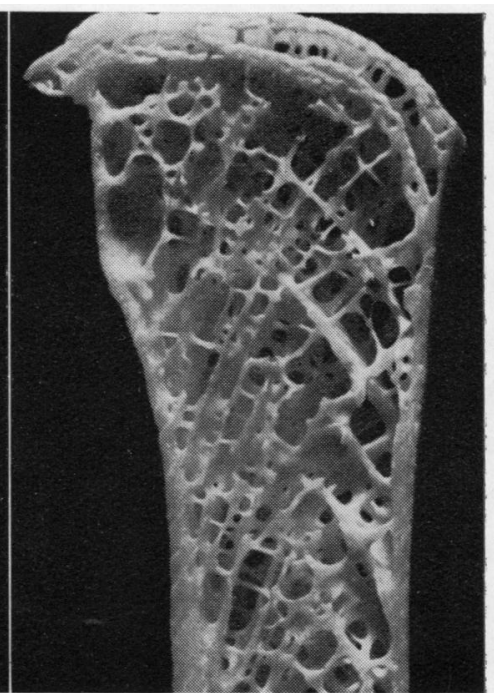

Fig. 3 Photographs of macerated iliac crests in (a) man 26 years; (b) man 62 years; (c) woman 78 years. Note 'osteoporosis' in aged with wide spacing of cancellous trabeculae and 'cancellization' of crest cortical bone. $\times 5$. 


\begin{tabular}{|c|c|c|c|c|c|c|}
\hline \multirow[t]{2}{*}{ Case No. } & \multirow{2}{*}{$\begin{array}{l}\text { Age } \\
(y r)\end{array}$} & \multicolumn{3}{|c|}{ Percentage of Measured Area Comprising } & \multirow{2}{*}{$\begin{array}{l}\text { Percentage } \\
\text { Mineralization }\end{array}$} & \multirow{2}{*}{$\begin{array}{l}\text { Maximum } \\
\text { Number of } \\
\text { Osteoid } \\
\text { Lamellae }\end{array}$} \\
\hline & & $\begin{array}{l}\text { Total } \\
\text { Bone }\end{array}$ & $\begin{array}{l}\text { Mineralized } \\
\text { Bone }\end{array}$ & Osteoid & & \\
\hline 1 & 5 & $23 \cdot 2$ & $23 \cdot 2$ & 0.04 & 99.8 & 2 \\
\hline 2 & 11 & $21 \cdot 4$ & $21 \cdot 3$ & 0.05 & 99.8 & 2 \\
\hline 3 & 12 & 25.9 & $25 \cdot 8$ & $0 \cdot 13$ & 99.5 & 2 \\
\hline 4 & 14 & $24 \cdot 8$ & $24 \cdot 4$ & 0.45 & $98 \cdot 2$ & 2 \\
\hline 5 & 17 & $26 \cdot 4$ & $26 \cdot 2$ & 0.13 & 99.5 & 2 \\
\hline 6 & 19 & $24 \cdot 4$ & $24 \cdot 2$ & $0 \cdot 12$ & 99.5 & 3 \\
\hline 7 & 20 & $16 \cdot 1$ & $16 \cdot 1$ & 0.04 & 99.7 & 2 \\
\hline 8 & 21 & $26 \cdot 6$ & $26 \cdot 3$ & 0.23 & 99.2 & 2 \\
\hline 9 & 21 & $28 \cdot 6$ & $28 \cdot 3$ & 0.34 & 98.8 & 3 \\
\hline 10 & 21 & $22 \cdot 7$ & $22 \cdot 5$ & 0.19 & $99 \cdot 2$ & 4 \\
\hline 11 & 22 & $22 \cdot 5$ & $22 \cdot 1$ & 0.36 & 98.4 & 2 \\
\hline 12 & 22 & 23.6 & 23.5 & 0.06 & 99.7 & 2 \\
\hline 13 & 22 & 18.9 & $18 \cdot 8$ & 0.11 & 99.4 & 3 \\
\hline 14 & 23 & $25 \cdot 2$ & $25 \cdot 1$ & 0.08 & 99.7 & 3 \\
\hline 15 & 24 & $26 \cdot 1$ & $26 \cdot 1$ & 0.05 & 99.8 & 3 \\
\hline 16 & 25 & $18 \cdot 2$ & $18 \cdot 1$ & 0.09 & 99.5 & 2 \\
\hline 17 & 25 & $22 \cdot 2$ & $22 \cdot 1$ & $0 \cdot 10$ & 99.6 & 4 \\
\hline 18 & 25 & $24 \cdot 1$ & $24 \cdot 0$ & 0.09 & 99.7 & 2 \\
\hline 19 & 25 & $24 \cdot 2$ & $24 \cdot 0$ & $0 \cdot 14$ & 99.4 & 2 \\
\hline 20 & 27 & $21 \cdot 0$ & $21 \cdot 0$ & 0.05 & 99.7 & 2 \\
\hline 21 & 28 & 19.5 & $19 \cdot 4$ & 0.09 & 99.6 & 1 \\
\hline 22 & 28 & $22 \cdot 1$ & $22 \cdot 1$ & 0.03 & 99.9 & 1 \\
\hline 23 & 31 & $25 \cdot 0$ & $25 \cdot 0$ & 0.02 & 99.9 & 1 \\
\hline 24 & 33 & $26 \cdot 6$ & $26 \cdot 3$ & 0.27 & 99.0 & 3 \\
\hline 25 & 36 & 18.0 & $17 \cdot 8$ & $0 \cdot 18$ & 99.0 & 1 \\
\hline 26 & 37 & $20 \cdot 2$ & $21 \cdot 0$ & 0.04 & $99 \cdot 8$ & 2 \\
\hline 27 & 46 & $18 \cdot 3$ & $18 \cdot 3$ & 0.04 & 99.8 & 2 \\
\hline 28 & 47 & $25 \cdot 0$ & $24 \cdot 8$ & 0.23 & $99 \cdot 1$ & 3 \\
\hline 29 & 53 & $25 \cdot 6$ & $25 \cdot 5$ & $0 \cdot 15$ & 99.4 & 4 \\
\hline 30 & 59 & $19 \cdot 4$ & $19 \cdot 3$ & 0.15 & $99 \cdot 2$ & 2 \\
\hline 31 & 60 & 21.9 & $21 \cdot 7$ & 0.20 & 99.1 & $\overline{3}$ \\
\hline 32 & 61 & $17 \cdot 7$ & $17 \cdot 7$ & 0.03 & 99.8 & 1 \\
\hline 33 & 63 & $16 \cdot 1$ & $16 \cdot 0$ & 0.15 & $99 \cdot 1$ & 1 \\
\hline 34 & 66 & 165 & 16.4 & 0.03 & $99 \cdot 8$ & 2 \\
\hline 35 & 70 & $15 \cdot 7$ & $15 \cdot 6$ & 0.09 & $99 \cdot 4$ & 2 \\
\hline 36 & 73 & $1 C \cdot 4$ & $10 \cdot 3$ & 0.07 & $99 \cdot 3$ & 2 \\
\hline 37 & 74 & $14 \cdot 0$ & $14 \cdot 0$ & 0.02 & 99.9 & 1 \\
\hline 38 & 77 & $1 C \cdot 3$ & 16.6 & $0 \cdot 14$ & $99 \cdot 2$ & 2 \\
\hline 39 & 78 & $6 \cdot 4$ & 6.4 & 0.03 & 99.5 & 2 \\
\hline 40 & 82 & $14 \cdot 0$ & 13.9 & 0.11 & $99 \cdot 2$ & 2 \\
\hline 41 & 93 & $16 \cdot 3$ & $16 \cdot 3$ & 0.01 & 99.9 & 1 \\
\hline
\end{tabular}

Table III Results of iliac crest quantitative histology in 41 male controls

\begin{tabular}{|c|c|c|c|c|c|c|}
\hline \multirow[t]{2}{*}{ Case No. } & \multirow{2}{*}{$\begin{array}{c}\text { Age } \\
(y r)\end{array}$} & \multicolumn{3}{|c|}{ Percentage of Measured Area Comprising } & \multirow{2}{*}{$\begin{array}{l}\text { Percentage } \\
\text { Mineralization }\end{array}$} & \multirow{2}{*}{$\begin{array}{l}\text { Maximum } \\
\text { Number of } \\
\text { Osteoid } \\
\text { Lamellae }\end{array}$} \\
\hline & & $\begin{array}{l}\text { Total } \\
\text { Bone }\end{array}$ & $\begin{array}{l}\text { Mineralized } \\
\text { Bone }\end{array}$ & Osteoid & & \\
\hline 42 & 5 & $20 \cdot 9$ & $20 \cdot 6$ & $0 \cdot 31$ & 98.5 & 2 \\
\hline 43 & 11 & $24 \cdot 4$ & $24 \cdot 3$ & $0 \cdot 12$ & 99.5 & 2 \\
\hline 44 & 16 & $20 \cdot 0$ & $20 \cdot 0$ & 0.03 & 99.9 & 2 \\
\hline 45 & 17 & $25 \cdot 2$ & $25 \cdot 0$ & $0 \cdot 17$ & $99 \cdot 3$ & 2 \\
\hline 46 & 17 & $26 \cdot 7$ & $26 \cdot 7$ & 0.04 & 99.8 & 2 \\
\hline 47 & 20 & 23.8 & $23 \cdot 6$ & $0 \cdot 16$ & $99 \cdot 3$ & 2 \\
\hline 48 & 22 & $17 \cdot 2$ & $17 \cdot 2$ & 0.0 & $100 \cdot 0$ & - \\
\hline 49 & 23 & $24 \cdot 6$ & $24 \cdot 5$ & 0.03 & 99.9 & 2 \\
\hline 50 & 28 & 20.9 & $20 \cdot 7$ & $0 \cdot 14$ & $99 \cdot 3$ & 2 \\
\hline 51 & 39 & $23 \cdot 6$ & $23 \cdot 5$ & 0.08 & 99.7 & 3 \\
\hline 52 & 41 & $25 \cdot 2$ & $25 \cdot 0$ & $0 \cdot 16$ & 99.4 & 2 \\
\hline 53 & 42 & 17.9 & 17.8 & 0.05 & 99.7 & 2 \\
\hline 54 & 44 & 20.8 & 20.8 & 0.06 & 99.9 & 1 \\
\hline 55 & 50 & $20 \cdot 3$ & $20 \cdot 1$ & $0 \cdot 18$ & 99.1 & 3 \\
\hline 56 & 56 & 21.8 & $21 \cdot 6$ & 0.19 & 99.1 & 3 \\
\hline 57 & 59 & 19.5 & 19.5 & 0.04 & 99.8 & 1 \\
\hline 58 & 62 & 13.0 & 12.9 & 0.07 & 99.4 & 2 \\
\hline 59 & 66 & 15.9 & 15.8 & 0.10 & $99 \cdot 4$ & 1 \\
\hline 60 & 68 & $16 \cdot 3$ & $16 \cdot 3$ & 0.05 & 99.7 & .2 \\
\hline 61 & 69 & 20.7 & 20.5 & 0.22 & 98.9 & 2 \\
\hline 62 & 69 & $26 \cdot 1$ & 26.0 & 0.08 & 99.7 & 2 \\
\hline 63 & 70 & 12.9 & 12.9 & 0.01 & 99.9 & 1 \\
\hline 64 & 77 & 16.4 & $16 \cdot 3$ & 0.05 & 99.7 & 2 \\
\hline 65 & 78 & $7 \cdot 7$ & $7 \cdot 7$ & 0.01 & 99.8 & 1 \\
\hline 66 & 82 & $7 \cdot 5$ & $7 \cdot 4$ & 0.12 & 98.4 & 2 \\
\hline 67 & $\begin{array}{l}02 \\
91\end{array}$ & 5.5 & 5.5 & 0.04 & 99.3 & 1 \\
\hline 68 & 93 & $7 \cdot 6$ & 7.6 & 0.0 & $100 \cdot 0$ & 1 \\
\hline
\end{tabular}

Table IV Results of iliac crest quantitative histology in 27 female controls 


\begin{tabular}{|c|c|c|c|c|c|c|}
\hline \multirow{2}{*}{$\begin{array}{l}\text { Age } \\
\text { (yr) }\end{array}$} & \multirow[t]{2}{*}{ Sex } & \multirow{2}{*}{$\begin{array}{l}\text { Number of } \\
\text { Observaticns }\end{array}$} & \multicolumn{3}{|c|}{ Percentage Measured Area Comprising } & \multirow{2}{*}{$\begin{array}{l}\text { Mineralization }(\%) \\
\text { Mean } \pm S E\end{array}$} \\
\hline & & & $\begin{array}{l}\text { Total Bone } \\
\text { Mean } \pm S E\end{array}$ & $\begin{array}{l}\text { Mineralized Bone } \\
\text { Mean } \pm S E\end{array}$ & $\begin{array}{l}\text { Osteoid } \\
\text { Mean } \pm S E\end{array}$ & \\
\hline$\geqslant 50$ & $\begin{array}{l}\text { Males } \\
\text { Females } \\
\text { Combined }\end{array}$ & $\begin{array}{l}28 \\
14 \\
42\end{array}$ & $\begin{array}{l}22.9 \pm 0.6 \\
22.2 \pm 0.8 \\
22.7 \pm 0.5\end{array}$ & $\begin{array}{l}22.8 \pm 0.6 \\
22.1 \pm 0.8 \\
22.5 \pm 0.5\end{array}$ & $\begin{array}{l}0.13 \pm 0.02 \\
0.10 \pm 0.02 \\
0.12 \pm 0.02\end{array}$ & $\begin{array}{l}99.4 \pm 0.1 \\
99.5 \pm 0.1 \\
99.5 \pm 0.1\end{array}$ \\
\hline$>50$ & $\begin{array}{l}\text { Males } \\
\text { Females } \\
\text { Combined }\end{array}$ & $\begin{array}{l}13 \\
13 \\
26\end{array}$ & $\begin{array}{l}16.2 \pm 1.3 \\
14.7 \pm 1.8 \\
15.5 \pm 1.1\end{array}$ & $\begin{array}{l}16.1 \pm 1.3 \\
14.6 \pm 1.8 \\
15.4 \pm 1.1\end{array}$ & $\begin{array}{l}0.09 \pm 0.02 \\
0.09 \pm 0.03 \\
0.09 \pm 0.02\end{array}$ & $\begin{array}{l}99.5 \pm 0.1 \\
99.5 \pm 0.1 \\
99.5 \pm 0.1\end{array}$ \\
\hline
\end{tabular}

Table V Summary of mean total bone values in 68 controls grouped according to age and sex

\begin{tabular}{llll}
\hline $\begin{array}{l}\text { Number of } \\
\text { Birefringent }\end{array}$ & \multicolumn{2}{l}{ Percentage of Cases } \\
\cline { 2 - 4 } Lamellae & $<50$ Years & $>50$ Years & $>60$ Years \\
\hline $0-1$ & 14.3 & 38.5 & 42.9 \\
2 & 59.5 & 50.0 & $57 \cdot 1$ \\
3 & 21.4 & 7.7 & 0.0 \\
4 & 4.8 & 3.8 & 0.0 \\
\hline
\end{tabular}

Table VI Incidence and number of birefringent lamellae in osteoid in control iliac crests

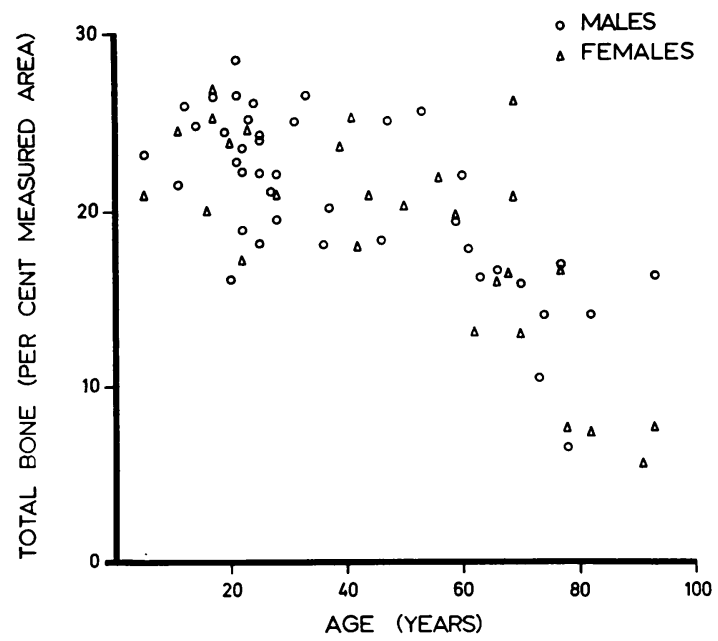

Fig. 5 Relationship between iliac crest total bone values and age.

There is a progressive bone loss during and after the fifth decade.

(Tables III and IV). The maximum number of birefringent lamellae observed in the osteoid seams are given in Tables III, IV and VI. The majority of seams include only one or two lamellae and the maximum of three or four observed in a few individuals occur in only very occasional seams. The number of lamellae shows some rough correlation with age in that all three cases with four lamellae

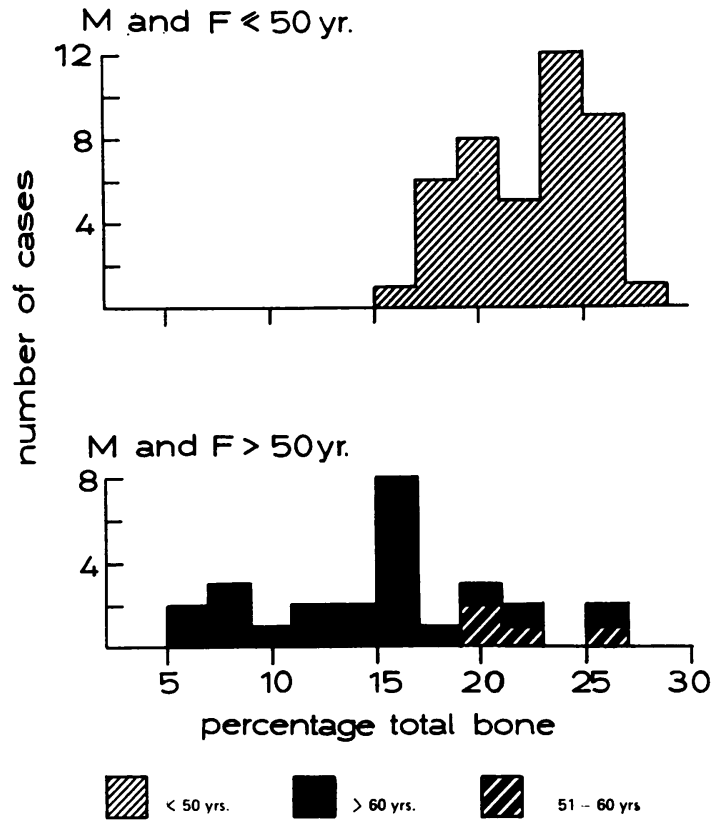

Fig. 6 Distribution of total bone values in men and women in the two age groups $₹ 50$ years and $>50$ years.

There is a relatively wide distribution of values in the $>50$ years group since this includes many aged subjects with low values and a few in the fifth and sixth decades with normal values.

were aged $<60$ years and the maximum number observed in individuals over this age is two.

\section{Discussion}

Although others have commented on the variability of bone density in different parts of the iliac crest the present results suggest this has been underestimated. 
Beck and Nordin (1960) examined samples of decalcified bone from the iliac crest of a single cadaver at $0.5 \mathrm{~cm}$ intervals behind the anterior superior spine and, using a semi-quantitative visual nine-point scale for assessing total bone mass, concluded that there were no significant differences at the various levels. These workers included cortical and cancellous bone in an area between the inner and outer tables of the iliac bone to a depth of about $1.0 \mathrm{~cm}$ from the surface. Garner and Ball (1966) used a more refined point-counting technique to determine the total bone mass in undecalcified sections in an area of cancellous bone measuring $0.5 \times 0.5 \mathrm{~cm}$ situated just beneath the cortex of the iliac crest midway between the inner and outer cortical tables. They investigated the variation in total bone mass in this region in four consecutive sites each $1.0 \mathrm{~cm}$ apart in postmortem material from two subjects. There was a slight but significant variation in relation to the site examined. Our results confirm these observations but in addition indicate that greater differences may occur in some individuals when the areas selected are at varying depths below the crest surface. In many iliac bones it is in the central region just below the crest surface that the density of bone trabeculae is least. These observations have some bearing on the site selected for iliac crest biopsy. In practice the biopsy site may be anywhere within that area of bone situated up to $2.0 \mathrm{~cm}$ below the crest surface, as we have been able to confirm in a number of patients who have later come to necropsy. For this reason we have quantitated the maximum area possible in each biopsy specimen. In recent years it has been the practice in this hospital to obtain iliac crest biopsies in the horizontal plane using a trephine with an internal diameter of $0.7 \mathrm{~cm}$. The specimen is a cylinder of bone comprising both inner and outer tables of compact cortical bone with intervening cancellous bone and measuring from 1.0 to $1.5 \mathrm{~cm}$ in length. The specimen can be divided lengthwise using a fine saw blade and the two halves embedded separately for the preparation of undecalcified and decalcified sections. It is possible to delineate in the sections an area of cancellous bone measuring about $1.0 \times 0.5 \mathrm{~cm}$ giving a fairly representative area of $0.5 \mathrm{~cm}^{2}$ comparable with a similar mean area of $0.7 \mathrm{~cm}^{2}$ in our control necropsy series.

We endorse the view expressed by Garner and Ball (1966) that specimens taken with small-bore trephines, whilst suitable for diagnostic purposes, are inadequate for quantitative assessment since they are too small and tend to fragment. If small specimens only are available they are best embedded entire and undecalcified sections prepared longitudinally to give as large an area as possible for quantitative study. Such blocks can later be decalcified to prepare sections for routine histological examination. Division of the specimen before the preparation of blocks for decalcified and undecalcified sections is best avoided on account of further fragmentation and transverse sections in particular provide a very small area of cancellous bone. Since our results indicate that there may be some variation in the total bone mass depending upon the plane in which sections are prepared from the biopsy it is worth marking the specimen at the time of its removal to allow correct orientation in the vertical plane before embedding.

There is fairly close agreement in the values obtained for the total bone mass determined by quantitative histology and by the volumetric method. The uniformly higher values obtained with the volumetric method may be due to trapping of minute amounts of air in the marrow-free samples, the use of unfixed material, and the inclusion of a greater proportion of dense cancellous bone derived from just beneath the cortical bone. This agreement justifies the use of thin microscopic sections provided the area measured is not too small.

The results of quantitative histology in the present 68 control cases conform with those of Garner and Ball (1966). They gave mean values of $18.5 \%$, $18.3 \%$, and $0.23 \%$ for total bone, mineralized bone, and osteoid respectively in 22 males and females aged < 50 years. The total bone figures in the present series are higher, probably because Garner and Ball counted an area of cancellous bone just below the crest surface, where the density of trabeculae is commonly low, whereas our data refer to larger areas. Wakamatsu and Sissons (1969) give a figure of $23.3 \%$ for total bone area in the iliac crest at 20 years of age falling progressively to $15.8 \%$ at 70 years of age. These figures are in keeping with our data, which show a progressive fall in total bone mass with age in both sexes. Saville (1965) and Garner and Ball (1966) in the case of the iliac crest and Dunnill et al (1967), Caldwell (1962), and Atkinson (1967) in the case of the vertebral body reported similar changes in bone density with age. Ball and Garner (1966) found a marked diminution of iliac crest total bone mass after the age of 50 years in a group of 41 control subjects. Dunnill et al (1967) suggested that their data could be interpreted as indicating a steady decline with age in the proportion of bone in vertebrae but that the trend had levelled out by the age of 55 years. On the other hand, Atkinson (1967) found a progressive increase in porosity of the central part of the body of the second lumbar vertebra after the age of 50 years. Our results for the iliac crest, together with those of Garner and Ball (1966) and Sissons, Holley, and Heighway (1967), show a continued diminution of bone well after the age of 50 
years. Vost (1963) reported the results of semiquantitative photometric observations of bone density in vertebrae and iliac crests and described a bimodal distribution in relation to age, but the bone came from random necropsies on patients whose diseases could have induced disuse osteoporosis. Like Dunnill et al (1967) our data are insufficient to construct distribution histograms of total bone for each decade. However: males and females in the age group $<50$ years do present a compact distribution compared with a wide spread of values in the case of individuals age $>50$ years (Fig. 6). In the latter group there is a mixture of individuals age $>60$ years with mostly low total bone values and others in the fifth decade with normal values. Only one individual age $>60$ years has a high normal value for total bone. The histograms suggest that the total bone varies little until the fifth decade but since there is a wide variation between different individuals it is possible that in some an earlier decline in bone mass is concealed. We have applied the technique suggested by Quandt $(1958,1960)$ and Sprent (1961) to determine the point at which this decline might commence. The method involves division of the observations into two groups and calculation of separate linear regressions, after eliminating the central observations to reduce the probability of contamination of one regression with observations from the other. The point of intersection of the two lines represents the change-over point. Dunnill et al (1967) applied this method to their vertebral data, but concluded that the decline in bone density with age was not large enough in comparison with the range of variation between their individuals for the shape of the curve to be determined. Calculation of the two regression lines for our iliac crest data for males and females combined gives a change-over point at the forty-seventh year. Calculation of regressions from the data of Garner and Ball (1966) gave a very similar change-over point during the forty-eighth year. Saville (1965), who used the weight of a standard sample of fat-free iliac bone as an index of bone density in 155 men and women between the ages of 20 and 85 years, also found a significant difference for women between the fourth and fifth decades.

Most studies of the effects of age on bone mass have been based on the analysis of collective data and there is still a need for longitudinal studies in individual subjects. Adams, Davies, and Sweetnam (1970) have attempted to do this by making certain radiological measurements on the cortical bone of the second metacarpal in 88 men and 86 women at an interval of 11 years, the initial ages varying from 55 to 64 years. They found a reduction in bone mass in some but not all the individuals. It is clear that the bone mass of any elderly individual will be dependent upon the mass attained at maturity and the rate of subsequent bone loss. The accumulated evidence favours the view that so-called senile osteoporosis is usually a manifestation of the normal aging processes (Sissons et al, 1967; Newton-John and Morgan, 1968; Vaughan, 1970) and is not necessarily pathological. Our histological observations on the pattern of cancellous bone trabeculae in the iliac crest are in keeping with the quantitative observations of Wakamatsu and Sissons (1969) that the reduced bone mass in the elderly is largely the result of a diminution in the number of trabeculae which are of relatively normal width but more widely spaced. In deciding whether or not any given bone sample shows an abnormal total bone mass it is clearly essential to take account of the patient's age. In the light of our results on the effect of age on total bone mass it is convenient to calculate control values for males and females together in two main groups, those aged $₹ 50$ years and those $>50$ years, respectively (Table V).

Woods et al (1968) re-emphasized that osteoid can be found in osteoporotic and normal bone as well as in osteomalacia. In 41 control iliac crests they found osteoid accounted for up to $5.0 \%$ of the cancellous bone. Garner and Ball (1966) found a slightly lower figure of up to $3.2 \%$ in 41 cases and in the present series the maximum figure observed was $1.8 \%$. The osteoid is widely and patchily scattered at the surface of the trabeculae and in our experience the seams do not include more than four birefringent lamellae when examined under the polariser. Because of the patchy distribution of osteoid it is important not to base quantitative studies on small and fragmented biopsies which may not be representative. This is of particular importance when studying pathological material. In moderate to severe degrees of osteomalacia the cancellous trabeculae are more or less uniformly covered by osteoid and most trabeculae are representative, but in lesser degrees of osteomalacia, occurring for example in renal osteodystrophy, there may initially be a patchy distribution of osteoid at the sites of previous bone resorption and quantitative study of small samples may give misleading results. This is particularly important when assessing serial biopsies taken from individual patients by a small-bore trephine. We agree with the suggestion of Woods et al (1968) that the number of birefringent lamellae present is the best indication of the width of osteoid seams since this avoids the pitfall of measuring apparently wide osteoid seams that are really normal seams cut tangentially. It may be difficult to distinguish between an excess of osteoid and osteomalacia on the basis of the absolute amount of osteoid present; 
a slight excess of osteoid may be due to the deposition of focal and abnormally wide osteoid seams in patients with a mineralization defect, or to widespread deposition of osteoid seams of normal width due to increased osteoblastic activity in the absence of a mineralization defect. Garner and Ball (1966) have stressed that in borderline cases the diagnosis of osteomalacia may be somewhat subjective. The finding of more than four birefringent lamellae in osteoid seams favours the presence of a mineralization defect since this is the maximum number of lines we observed in control material and then in only $4.4 \%$ of 68 cases. Woods et al (1968) similarly found a maximum number of three lines in their 41 controls. In our hands staining of the so-called 'calcification front' by solochrome cyanin $\mathrm{R}$ has given variable results and we have been unable to utilize this technique as an aid to the diagnosis of osteomalacia.

We wish to thank Dr J. Ball for advice at the outset of this study and Mr J. R. MacLennan, FIMLT, for valuable technical assistance. This work was supported by a research grant from the Board of Governors of the United Newcastle upon Tyne Hospitals.

\section{References}

Adams, P., Davies, G. T., and Sweetnam, P. (1970). Osteoporosis and the effects of ageing on bone mass in elderly men and women. Quart. J. Med., 39, 601-615.

Atkinson, P. G. (1967). Variation in trabecular structure of vertebrae with age. Calc. Tiss. Res., 1, 24-32.
Ball, J. (1957). A simple method of defining osteoid in undecalcified sections. J. clin. Path., 10, 281-282.

Beck, J. S., and Nordin, B. E. C. (1960). Histological assessment of 을 osteoporosis by iliac crest biopsy. J. Path. Bact., 80, 391-397.

Caldwell, R. A. (1962). Observations on the incidence, aetiology and pathology of senile osteoporosis. J. clin. Path., 15, 421-431.

Dunnill, M.S. (1962). Quantitative methods in the study of pulmonary pathology. Thorax, 17, 320-328.

Dunnill, M. S., Anderson, J. A., and Whitehead, R. (1967). Quantita- $\overline{\bar{G}}$ tive histological studies on age changes in bone. J. Path. Bact., 94, 275-291.

Garner, A., and Ball, J. (1966). Quantitative observations on mineralised and unmineralised bone in chronic renal azotaemia and 0 intestinal malabsorption syndrome. J. Path. Bact., 91, 545-561.

Hennig, A., and Meyer-Arendt, J. R. (1963). Microscopic volume determination and probability. Lab. Invest., 12, 460-464.

Newton-John, H. F., and Morgan, D. B. (1968). Osteoporosis: disease or senescence? Lancet, 1, 232-233.

Quandt, R. E. (1958). The estimation of the parameters of a linear regression system obeying two separate regimes. J. Amer. 0 statist. Ass., 53, 873-880.

Quandt, R. E. (1960). Tests of the hypothesis that a linear regression $\mathrm{G}$ system obeys two separate regimes. J. Amer. statist. Ass., 55, $\rightarrow$ 324-330.

Sacker, L. S., and Nordin, B. E. C. (1954). A simple bone biopsy $Y$ needle. Lancet, $1,347$.

Saville, P. D. (1965). Changes in bone mass with age and alcoholism. 음 J. Bone Jt Surg., 47A, 492-499.

Sissons, H. A., Holley, K. J., and Heighway, J. (1967). Normal bone structure in relation to osteomalacia. In L'Ostéomalacie, edited by D. J. Hioco, pp. 19-37. Masson, Paris.

Sprent, P. (1961). Some hypotheses concerning two phase regression lines. Biometrics, 17, 634-645.

Vaughan, J. M. (1970). The Physiology of Bone, p. 217. Clarendon Press, Oxford; University Press, London.

Vost, A. (1963). Osteoporosis: A necropsy study of vertebrae and iliac crests. Amer. J. Path., 43, 143-151.

Wakamatsu, E., and Sissons, H. A. (1969). The cancellous bone of the iliac crest. Calc. Tiss. Res., 4, 147-161.

Williams, J. A., and Nicholson, G. I. (1963). A modified bone-biopsy drill for outpatient use. Lancet, 1,1408 .

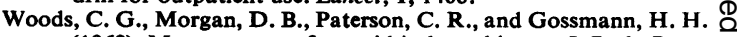
(1968). Measurement of osteoid in bone biopsy. J. Path. Bact. 95, 441-447. 